International Review of Research in Open and Distributed Learning Volume 16, Number 6

November - 2015

\title{
Using MOOCs at Learning Centers in Northern Sweden
}

Anders Norberg' ${ }^{1}$, Åsa Händel${ }^{2}$ and Per Ödling ${ }^{3}$

1 Umeå University, ${ }^{2}$ Arvidsjaur Learning Center, ${ }^{3}$ Lund University

\begin{abstract}
This paper describes the use of globally accessible Massive Open Online Courses, MOOCs, for addressing the needs of learners at community learning centers in Northern Sweden. The Scandinavian "study circle" concept is used to facilitate the studying of MOOCs, thereby forming "blended" or "glonacal" courses. Although the technical possibilities for Swedish universities to offer accessible education are steadily increasing, most universities do not, at present, prioritize courses for off-campus students. The available web courses in asynchronous formats are also difficult to master for untraditional learners and leaves the local learning centers with limited possibilities. Therefore a Nordplus Horizontal project 2014-2016, with partners in three Nordic countries, is developing models for the use of MOOCs in learning centers and organizations. A small pilot course case at the learning center in Arvidsjaur and its outcome is presented, including the interactions with Lund University which has an ongoing piloting project on use and examination of MOOCs. This concept development is discussed as a blended learning design and as a "glonacal" phenomenon with Marginson and Rhoades' "glonacal agency heuristics". Possible future scenarios are outlined.
\end{abstract}

Keywords: Open Education; MOOC; Wrapped MOOC; Glocalization; Glonacal Agency Heuristics; Blended Learning; Study Circle; Learning Center; Akademi Norr; Lund University. 


\section{Introduction}

\section{Disposition of the Paper}

First a background is given on education access in sparsely populated parts of Northern Sweden, the present state of stakeholders, and the involved project initiatives. Then a small pilot case from the learning center in Arvidsjaur is presented. Finally, this idea is analyzed as a variety of blended learning and with an actor analysis on the background of Marginson and Rhoades' glonacal heuristics (2002).

The questions in focus for this paper are:

a) How can Swedish local learning centers offer, adapt, and use MOOCs instead of vanishing national courses?

b) How can a new learning opportunity, combined by using global and local solutions as well as asynchronous and synchronous modes, be understood, and what are the possible future implications?

\section{Diminishing Access to Education}

With its $450000 \mathrm{~km}^{2}$, Sweden is the fifth largest country in size in the European Union but has a total population of only 9,6 million and an average density of 23 inhabitants per $\mathrm{km}^{2}$. In contrast, the European Union has 112 inhabitants per $\mathrm{km}^{2}$ (SCB, 2013). The population density in southern and mid-Sweden is much greater than in the north: about 8 million people live in the southern third of the country. For the two northernmost regions, Norrbotten and Västerbotten, the population density is 2,5 and 4,7 inhabitants per $\mathrm{km}^{2}$ respectively. The vast majority live along the coast of the Gulf of Bothnia in the cities of Umeå, Skellefteå and Luleå. The sparsely populated inland areas have suffered from serious depopulation from the 1950's and onwards. Many of the traditional jobs in forestry and agriculture have disappeared, and new jobs in the service and knowledge sectors are limited. These areas are nationally strategic as they are rich in mineral resources, forests, hydro- and wind power, and popular for tourism. The new jobs that emerge, often require skills that the local educational systems have difficulties to match. One example is the important high-tech winter car testing industry (Nybacka, Larsson \& Ericsson, 2007). Higher education is accessible along the coast in the university cities of Umeå and Luleå. For the inland communities, this means a brain-drain because they see young people leaving but not returning. For lifelong learners (students over the age of 25), the coastal campuses are beyond daily commuting distance, and the average education level inland is - as one can expect - low in national comparison. At the same time, these inland municipalities are often the initial placement for asylum-seekers mainly from the Middle East and Africa. Many of these get no access to higher education, both for formal and geospatial reasons.

This work is licensed under a Creative Commons Attribution 4.0 International License. 
In 2010, the increase of "distance education" in Sweden was expected to continue (Amneus 2010), but by 2014 the number of courses and programs offered had instead decreased (UHÄ, 2014). Universities now seem to be concentrating on campus-based programs of education.

\section{Learning Centers and Local Development}

Because of the long distances to a university campus, rural communities try to be proactive. Some representation of higher education in the local community, big or small, is seen as a necessity for local development (Danielson, Grepperud \& Roos, 2015). The political motivations vary but concerns are about regional development in a knowledge society, and the learning centers, are often connected to business development. A 2005 European Commission assigned study found local learning centers existed in varying forms all over Europe (Buiskool, Grijpstra, van Kan, van Lakerveld \& den Oudendammer, 2005). Grepperud and Thomssen (2001) categorizes the functions of Norwegian and Swedish learning centers as three "M":s, "Motor, Mötesplats, Mäklare" ("engine" for development, "meeting place" for students, "broker" of education). Learning centers also offer career counseling and exam proctoring services (Glesbygdsverket 2003). For the past two decades, a central technology of the learning centers has been the video conference studio bringing students together for online seminars and lectures. Today, technological development allows video to be streamed to personal computers in homes and mobile devices as well. The idea and work mode of learning centers is therefore meeting challenges and evolving (Grepperud, Danielsen \& Roos 2015). The learning centers want to support a social dimension of learning, which also makes learning more visible in the local community (Lögdlund 2008). MOOCs will bring new possibilities and challenges to the learning center (Danielson, Roos, \& Grepperud, 2015).

\section{The Swedish Study Circle Tradition}

The classic Swedish "study circle" concept has been and still is important in Sweden: it is the regular local gathering of learners for studying together. This goes back to Oscar Olsson, teacher and parliament member and active in the temperance movement at the beginning of the 20th century (Larsson \& Nordvall, 2010). From teaching groups in the temperance movement, in 1902 he formed a model of studying together that was more flexible and resource-efficient. The study circle allowed for and encouraged questions and discussions between individual learner's to aid and improve learning. It was not led by a teacher, but by a host, a "circle leader." It has since been an important tool for political and religious movements, temperance organizations, trade unions, sports movements, and NGOs. Some approved study material or study plan is used. This model can also integrate new technology. When the Swedish national radio broadcasting service, Radiotjänst, in late 1920's, began broadcasting series of lectures in different subjects, "radio circles" emerged. The new technology was combined with the collaborative learning format of the study circle. People gathered to listen to lectures in front of a radio set, afterward discussing its message. There was even a national conference for radio circle leaders (Radiotjänst, 1933).

This work is licensed under a Creative Commons Attribution 4.0 International License. 


\section{The Perspective of the Universities in the Region}

For the universities in Northern Sweden, the extension of access to education has been an important task since their foundation in the 6os and 70s. Early distance education often built on a model with concentrated face to face periods on campus or other meeting venues and selfdirected asynchronous studies at home. As educational technologies have developed, they have been incorporated by universities to increase educational access: video tapes, video conferences, CD-ROMs, e-mail and LMS's. The institutions had a spectrum of objectives such as reaching more students; testing new technology; showing political policy awareness; and cooperating with local communities. A considerable era of expansion occurred in the late 90s when EC structural funds ESF 3.5 were used by communities to involve universities in development projects for increased educational access. This kind of funding is no longer available. Flexible educational offerings by universities directed to address local needs have become fewer. One reason for this is changes to the funding system. Sweden has no tuition fees for education for its own or other EU citizens. Instead, universities are compensated by the state first for the registration of a student on a course and additionally for a student's completion of a course. Because of an adjustment in the compensation model, the completion of courses is favored over registration. This has caused a capacity transfer where universities shift from offering shorter courses to instead focusing on attracting students for program enrollment on main campuses. Concerning offering MOOCs, the Swedish universities have no regular funding, and they seem to be hesitant, although some of the top ranking institutions, like Karolinska Institutet and Lunds University, are now running MOOCs.

\section{Are MOOCs a Part of a Solution?}

MOOCs are categorized mainly as cMOOCs and xMOOCs. The former is modeled after the original MOOC course from the University of Manitoba in 2008, with George Siemens and Stephen Downes as initiators. cMOOCs focus on knowledge creation and participation in connection with connectivist theory (Siemens, 2013). An xMOOC is an online scalable course typically from a world-class university, with lectures, assignments, and quizzes. Pedagogically, it resembles traditional setups and focuses on knowledge acquisition. Both kinds have some characteristics in common. They are: tuition-free for the most part; non-selective in enrolment which is unlike Swedish education but welcomed by the untraditional learner; unclear concerning formal credit value; offered in English - which for Swedish students is often acceptable although support can be needed. The following refers mainly to xMOOCs.

This work is licensed under a Creative Commons Attribution 4.0 International License. 


\section{A Design for Use of M00Cs at Learning Centers}

There is a customized design concept under implementation including MOOCs in the project "Global Cloud Services - Local Lifelong Learners". The setup is as follows:

a) Learning center staff identifies learning needs in the regional development context.

b) If a university in the region cannot supply an appropriate solution to the learning need, available MOOC alternatives are examined.

c) A suitable MOOC course is found and marketed locally as a study circle function with weekly or bi-weekly study meetings at the learning center.

d) Students register for the MOOC and meet local peers to organize. The group can be quite small; from 3 or 4 participants.

e) A study circle leader is appointed among the learners to function as a host for meetings.

f) The course can be augmented by adding local content, e.g. visits to workplaces relevant for the course or an expert visiting the group for discussions in person.

g) A course certificate can be obtained from the MOOC platform, alternatively national recognition by cooperation with a Swedish university arranging a local examination is an option.

This concept gives the learning center a new tool for addressing local learning needs. It gives the asynchronous course a social face-to-face support environment that will be helpful for course completion and enhance learning. It liberates the learning center from being dependent on regional or national universities' education offerings. It also offers a more complex social network. For example, students have two layers of peers - internationally through the MOOC course forum and locally in the study circle.

The Nordplus Horizontal project "Global Cloud Services - Local Lifelong Learners" is funded by the Nordic Council of Ministers, an intergovernmental body. Partners are Akademi Norr, an association of 13 northern Sweden communities with learning centers (Roos, Grepperud \& Danielsen 2015); the city of Skellefteå with a multi-institutional campus; Lederne, a Danish association of managers; and Fjarkennsla, an Icelandic e-learning firm. The main objective is to try out models for contextualizing MOOCs in collective local settings. Within this project, MOOC courses are combined with study circles, the results researched, and the design enhanced continuously.

Parallel to the "Global Cloud Services" project, Akademi Norr has cooperation with Lund University about providing an examination for students taking MOOCs, awarding course certificates from Lund University. The cooperation is primarily directed towards groups that have 
difficulties entering the job market such as unemployed youth, newly arrived immigrants, and the disabled. This cooperation is coordinated with the project.

The first MOOC course in the project started in October 2014 with a local group in Arvidsjaur, Sweden, which took the course "Intro to the Design of Everyday Things" at Udacity.

Setting. Arvidsjaur is a traditional place for the Sami people, and is also renowned for its winter car testing activities and its tourism. Around 6500 people live in the municipality. The learning center is co-located with the municipal labor market development unit, office for refugees and EU project activities. Arvidsjaur is with its learning center a member of the association Akademi Norr, mentioned above.

Participants. Two men and three women aged 17-31, all of different nationalities, were recruited for their interest in the MOOC way of studying by the learning center manager, who also participated as a sixth learner. The learners were recruited by networking in and around the learning center. Of the participants, three had a university education, one had a vocational education and two were still attending upper secondary school.

The course "Intro to the Design of Everyday Things" was chosen for good reviews online and for being of general interest. The course was "self-paced", meaning that it could start any time. It comprised multiple short lectures in combination with design assignments and quizzes. In addition to videos discussing problem solutions, there was an active forum online for communication among learners. The final assignment was to design a user interface for a timebank app for a mobile device.

Method. Data collection was done by semi-structured interviews: four persons were interviewed in the learning center and one via Skype. The interviews were of piloting character and were aimed at describing student experiences of to the online course itself, then of the study circle, and finally how this formed a combined experience. Content analysis was used for the transcribed interviews. As more courses are completed, the method will be adjusted. The interviews available to this date do not provide a saturated understanding, but prepares for further study in a following Design-Based Educational Research project, enhancing the design and evaluating results in cycles (See Design-Based Research Collective, 2003).

Results. Only one person said she would have chosen to take this course by herself. One respondent says, "we did not have a common interest to join the course...it was rather like that we would like to have a new experience". None had participated in any online or distance course earlier, but two had heard about MOOCs. The learners were satisfied with the course, and with their participation. The English language offered a challenge as some were more skilled than others. What was difficult was mostly the special discourse of design concepts. Two mentions the term "affordances," which seem to have no clear translation in some other languages. A Swedish 
male who declared that he had his language skills thanks to video-gaming said that he could have given up the course at this stage: "...to afford something is kind of to have money enough...it complicated it a lot, and I would soon have lost interest if I had done this all alone...but when we could discuss it in the group, it became different." The other male mentioning "affordances" said: "This with affordance. The first time I heard...affordance then what's this... but then I (came to) see everything as affordances or signifiers." There were some smaller cultural issues. A young girl, who recently had arrived from a non-European country, said about the final assignment task to design a time-bank exchange app for a smartphone: "In Europe time is like gold...if we look at Africa and Asia time is not that necessary you know." (Interpreted meaning: not looked upon as a value in the same way).

During the six-week course, there had been synchronous meetings every Monday evening at 7 , lasting for one hour. Not all could participate every time. The study center manager led the meetings to start with, but this task was on a few occasions managed by another participant. The intended examiner, a professor from Lund University, called in a few minutes to some meetings to reduce any tension among the students about the upcoming examination. In the group, the videos and assignments for the previous week were discussed, and also the agenda for the coming week. All of the participants emphasized that the group had been important for pacing the studies and for getting things done and for finishing the course. However, the younger participants still in high school did not have much time to study as they were ambitious in school as well, and they were often supported by the older participants. This was accepted in the experiment. One girl says: "I and the other girl here, we were talking it through, but the others were really young, we were a support for them" and two participants meant that it was better if all in a study group were on similar level. The group meetings were important as they; a) formed a work schedule, helpful to get things done: "you feel you have the responsibility to watch it (the videos) and share the opinions"; b) enabled reflection and discussion: "when we met on Monday I asked if I did not understand and we could talk about it." Two students also reported lively group discussions where all had differing interpretations of an assignment concerning design elements of a rolling staircase. The course forum was not used (only one person reports trying), which was due to the existence of the local group. Four of the participants said that they could have studied the course by themselves, if motivated by the subject. The two youngest just said they must prioritize school instead, but that they had much valued the help of others.

Examination of learning. After course completion, a professor from Lund University visited Arvidsjaur and performed a verbal course examination of five of the participants (not the learning center manager). The examining interviews were done individually and lasted up to an hour covering both the theoretical concepts introduced during the course and the practical assignments. The grading was only "pass" or "fail." They all passed and were given a certificate from Lund University of the same kind as if they had taken part in a contracted course. A more complex grading has been discussed for future examinations. In particular there have been discussions on how to handle weak students with low self-esteem that have put considerable 
effort into studying the course but have not reached all of the course goals. A "fail" on a course would risk further lowering their will to take on new challenges and set goals for their lives.

\section{Two Theoretical Lenses}

\section{Theoretical Lens I: Blending Spaces or Time Modalities?}

When considering the discourses of technology and education, a clear consciousness of "place" and "transport" is shown (Meyer, 2005). "Distance learning," "education distribution," "remote student" - all point at a place as the radiation source of teaching or even learning. Still, much "distance teaching" has a classroom idea in the conceptual background; lectures are recorded or synchronously broadcasted, and LMS's replicate classroom functions. "Blended learning" is often understood as the use of an online environment in combination with classrooms; it all becomes a "blend of places." If a course is seen in this way, it seems to promote content distribution logistics as the central educational function. The metaphor of transportation of fresh goods to far-off places also brings in value propositions about transportation damages of goods, creation and consumption, and the normal and the exception.

There are alternative perspectives that can be of help, freeing up our thought from the place perspective. If "blended learning," which is a very problematic but commonly used term (Oliver \& Trigwell, 2005), is applied to the distinction synchronous /asynchronous instead of classroom /online, another perspective of how to use ICT tools in education appears. We have an increasing number of new digital synchronous and asynchronous tools, but we also have older ones in the mix; for example, the classroom as a synchronous tool and the book as an asynchronous one. Therefore, a current education design dilemma is how to combine carefully chosen tools in a course process involving students at one or several places and during varying time access conditions. These kinds of blended models have been described in Power's "Blended online learning" (2008), in Norberg, Dziuban and Moskal's time-based blended learning model (2011), and recently as "blended MOOCs" or "distributed flips" (Sandeen, 2013). A human is bound to be somewhere, more or less social and beneficial, when learning. The learner is not in the cloud. A co-located place for synchronous peer interaction, such as a learning center, can be of good use.

Recently, the concept of a "wrapped MOOC", a course with ordinary students as the asynchronous part of the course in combination with face-to-face lessons with the teacher, has been tested and discussed. An example is when Stanford's AI course on Coursera was used at Vanderbilt University (Bruff, Fisher, McEwen \& Smith, 2013). Stephen Downes remarks that whatever a "wrapped MOOC" is, it is not a MOOC because it is not open any longer (Downes, 2013). The study circle model presented here is different, as it does not have a teacher, but it is essentially a get-together of students of the same course, and not closed. It does not have the problems with syncing campus schedules with MOOC schedules that were both detected by Caulfield when doing "distributed flips" with MOOC content (2013).

This work is licensed under a Creative Commons Attribution 4.0 International License. 


\section{Theoretical Lens II: Glonacal Agency Heuristics}

Which words and concepts can be useful for imagining the global in relation to the local in a case such as with MOOCs at a learning center? "Glocalization" addresses how the global must be adapted to the local, but misses the national level. In the present time, the national level may not seem so actively involved in MOOCs, but is important in the context as funder and founder of universities for national purposes. "Marketization" mainly relates to the tension between national state control and market control of higher education. Is "globalization" the word we are seeking? Held, McGrew, Goldblatt and Perraton (1999) defines it as "the widening, deepening and speeding up of worldwide interconnectedness, " but it may make us think of the global, national, and local as a hierarchy or as Russian dolls of decreasing size placed one inside the other. This may not be helpful in itself as there are reciprocal links, interactions, flows, and relations between the global, the national and the local in all directions. Marginson and Rhoades (2002) capture this with their "glonacal agency heuristics" model. "Glonacal" means global + national + local. For imagining the glonacal they construct a non-hierarchical hexagon with agencies (organizations) and human agency (people who have agency) at the three glonacal levels forming six interdependent nodes, and it then describes relations between them as non-hierarchical and reciprocal; the flows go in all directions. Below we provide an attempt to use the glonacal model for capturing the presented design of MOOC courses. For this, we could also map out a regional level such as the EU European Higher Education Area, EHEA, between the global and the national. Below we discuss the actors and stakeholders on these three levels (global-nationallocal) and two kinds of agencies: agencies of organizations; and human individual or collective agencies. What can these agencies and agents see as possibilities or threats in a MOOC case like ours?

\section{Agent Analysis on Glonacal Basis}

The MOOC provider, usually a highly ranked university, is typically a local or national agency. The political and strategic motives for MOOC providers vary. Fiona Hollands finds, in 83 interviews with university leaders, the following: extending reach and access, building and maintaining brand, improving economics by reducing costs or increasing revenues, improving educational outcomes, innovation in teaching and learning, and conducting research on teaching and learning (Hollands, 2014). The MOOC providers must balance traditional factors as tuition fees, campus environments, and national regulatory frameworks while trying out something new. They believe that some parts of their teaching, usually a part connected to research priorities, are of global relevance and quality. A MOOC can thereby become a preliminary claim in a future global education provision. Research and education now go hand in hand from the local to the national and on to the global level. The MOOC providers may look upon their attracted MOOC students as their experimental global cloud students, and probably do not mind that some of them are working in supported groups in Northern Sweden. Inside the university, the engagement in MOOCs is often a result of human agency - people with ideas, enthusiasm, and influence.

This work is licensed under a Creative Commons Attribution 4.0 International License. 
The MOOC platforms can be seen as global agencies. These are exemplified by the "for-profit" platforms like Coursera or Udacity, or by the "not-for-profit" like EdX or Future-learn, which are ventures in cooperation between universities. They bring MOOC courses to students by providing their advanced LMS platform solutions and course marketing to the well-chosen MOOC providers, for a fee or cost. These platforms have made an important innovation - the scalability of the functions of a course, thereby solving a lot of organizational problems which the local university still has on campus. The visions of radical change are more often found on the global platform level than on the MOOC provider level where there are more traditional interests to balance and satisfy as well. It is interesting to note that Coursera is looking for test centers and meeting places, and some MOOCs offer automatic meeting suggestions with nearby students at cafeterias for example - acknowledging social needs to meet and interact with peers.

A Swedish university is a local or national agency. Here "local" should not be understood as value-laden. Today this local agency normally prioritizes international research excellence measured in publishing, citations, and rankings, counting on that this will also automatically mean education excellence status and attractiveness for students as well. In the best case, it will attract competitive high-performing students that almost teach themselves. Recruitment of untraditional students to distance education customized to fit local needs is usually not an attractive area for expansion. The connection between research and education seems strong here, but the coin has a flip side. The more specialized the research becomes in the hunt for global excellence, the weaker the capacity to satisfy a broad spectrum of education needs around the university site becomes. Here a discrepancy appears. The local region around any university is asking for both education and research services in an increasing number of knowledge disciplines. Their university, often thought of as a full-service provider, has become more of a global specialized institution. This development further decreases the likelihood of rural areas being serviced with higher education.

A local university can start a MOOC itself. In Sweden, the universities have asked the national agency of higher education for financing of MOOCs, as education for Swedish and EU citizens is tuition-free and state funded. This has not been granted. Universities can also "wrap" MOOCS as earlier described, but no such experiments are known to have been carried out in Sweden below Ph.D. studies.

We also have local human agency, playing into the local and national agencies' policy discussions. One example comes from a professor in telecommunications at Lund University, Per Ödling. He has described a risk scenario for Swedish universities that do not refresh their policies and practices and adapt to youth culture and technology (Ödling, 2013). He has proposed a "University of Sweden" (Ödling, Källström \& Lagergren, 2013) to make globally available for education the best of Swedish research-based knowledge. The "University of Sweden" would focus on quality control and examination of students who learn in net-based courses, such as MOOCs, 
independent of the provider. That is also what Lund University has prototyped in Arvidsjaur, and more is to be expected.

Northern Sweden's local learning centers and their associations are also local agencies, in the glonacal model. They work in their communities with higher education offerings as a tool for development of their traditional economy into a knowledge economy. It is a question of community survival in a time of depopulation and brain-drain and the forming of modern local knowledge economies. Although the learning center is sometimes seen as a university's remote node in a hierarchical model, a local learning center is not owned by the university, but by the local community. It can thereby alter its ontology and try to become more of a global learning center instead, and try to connect to other education providers on MOOC platforms. The potential students are not only the traditional ones; consequently, they may need support and feedback that an asynchronous web course seldom provides to learners outside a higher education culture. The use of study circle methodology can provide a solution.

What remains of the glonacal model in this Swedish case is the national agency. A national study on possibilities and risks with both use and provision of MOOCs has been started at the Swedish Higher Education Authority by government decision in March 2015.

\section{Two Possible Future Development Scenarios}

We have here formulated the problem of education access in remote communities in Sweden and suggested as well as implemented a design for addressing this problem. From the point of view developed from the learning center perspective, two interesting future scenarios arise.

\section{An xMOOC-Kind of Future Scenario:}

Asynchronous scalable global courses and programs from universities specialized in specific knowledge areas are accessible worldwide. These are customized and combined to provide each student a unique education. Big campuses, smaller branch campuses, and learning centers all become multi-institutional learning environments with different offerings of labs, mentoring, and functions. Exams are run by local bodies - universities or third-party assessors, by the MOOC provider or by a combination of both. Universities provide their own MOOCs for global students in their research specialties.

\section{An Alternative cMOOC-Kind of Scenario:}

Universities can proactively try to become more consciously glonacal; as such, they still compete in a global arena both with their research and with their associated specialized and globally accessible courses. At the same time, they work locally with communities to find ways to integrate campus education and what is now decentralized and distance education into new education logistics. Students on campus study together with other students in learning centers, in 
workplaces, and with students dispersed around the world. They have varying learning environments but construct their learning together under teacher inspiration and guidance. When needed, MOOC courses from other universities are used, but the university in the region works to create relevant courses and to support student learning in a constructive mode.

\section{Conclusion}

Our experiment was small but results encourage further actions. The understanding of this design has increased, and the learning center in Arvidsjaur has a new tool. The learning centers are often looked upon as an improvised construction in a context of depopulation, brain drain, general crisis, and long distance to the nearest campus. However, they may turn out to be a model for a future environment of education: a learning space serving local students but connected to many universities around the world. The learning centers can work actively at the intersection of the global, the national and the local. They can emerge as Foucauldian heterotopias (Foucault, 1984), connecting many places into one.

\section{Acknowledgements}

The authors acknowledge the support of the Nordplus Horizontal Program and EIT Digital for this work.

\section{References}

Amneus, I. (2010). Kartläggning av distansverksamheten vid universitet och högskolor. Stockholm: Högskoleverket.

Bruff, D., Fisher, D., McEwen, K. \& Smith, B. (2013). Wrapping a MOOC: Student perceptions of an experiment in blended learning. MERLOT Journal of Online Learning and Teaching, $9(2)$.

Buiskool, B-J., Grijpstra, D., van Kan, C., van Lakerveld, J. \& den Oudendammer, F. (2005). Developing local learning centres and learning partnerships as part of Member States' targets for reaching the Lisbon goals in the field of education and training: A study of the current situation. Research voor Beleid. Study assigned by the European Commission, DG Education and Culture. University of Leiden. 
Caulfield, M. (2013). The Distributed Flip. Transcript of presentation at InstructureCon. Retrieved 2014-10-20 from http://hapgood.us/ 2013/06/26/the-distributed-flippresentation-for-instructurecon-2013/

Danielsen, Å., Grepperud, G. \& Roos, G. (2015). Levende studie - og læringssentra? Funksjoner og framvekst. Septentrio Reports no 2, University of Tromsø. Retrieved from http://dx.doi.org/7.3407

Design-Based Research Collective (2003). Design-based research: An emerging paradigm for educational inquiry. Educational Researcher, 32(1), 5-8, 35-37. Retrieved 2014-08-01 from http://www.designbasedresearch.org/reppubs/ DBRC2003.pdf

Downes, S. (2013). MOOC - The Resurgence of Community in Online Learning. Transcript of presentation. May 30, 2013. Retrieved 2014-10-20 from http://halfanhour.blogspot.se/2013/05/mooc-resurgence-of-community-in-online.html

Foucault, M.(1984) Of Other Spaces, Heterotopias. Architecture, Mouvement, Continuité 5, p.4649.

Glesbygdsverket (2004). Lärcentra 2003 - Sammanställning av enkätsvar. Östersund: Glesbygdsverket.

Grepperud, G., Danielsen, Å. \& Roos, G. (2015). Levende studie- og læringssentra? Utviklingstrekk of utfordringer. Septentrio Reports no 4, University of Tromsø. Retrieved from http://dx.doi.org/7.3409

Grepperud, G., \& Thomsen, T. (2001). Vilkor for et regionalt utdanningslyft: vurdering av Studiesenteret på Finnsnes 1996-2001: sluttrapport. Troms, Harstad: U-VETT Universitetet i Troms, Högskolen Harstad.

Held, D., McGrew, A., Goldblatt, D. \& Perraton, J. (1999). Global transformations: politics, economics, and culture. Cambridge: Polity Press.

Larsson, S. \& Nordvall, H. (2010). Study Circles in Sweden: An Overview with a Bibliography of International Literature. Linköping: Linköping University Electronic Press.

Löglund, U. (2008). Lärcentra som mäklare av högre utbildning? Pedagogisk Forskning i Sverige, 13(2), pp. 103-122.

Marginson, S. \& Rhoades, G. (2002). Beyond national states, markets, and systems of higher education: A glonacal agency heuristic. Higher Education, 43, p. 281-309. 
Meyer, K.A. (2005). Common metaphors and their impact on distance education: What they tell us and what they hide, Teachers College Record, 107(8), pp. 1601-1625.

MOOCs@Edinburgh Group. (2013) MOOCs @ Edinburgh 2013: Report \#1. Retrieved 2014-1020 from http://hdl.handle.net/1842/6683

Norberg, A., Dziuban, C. \& Moskal, P. (2011) A time based blended learning model. On The Horizon, 19(3), pp 207 - 216.

Nybacka, M., Larsson, T. \& Ericsson, Å. (2007). Collaboration in automotive winter testing. Trends in Computer Aided Innovation, 250, pp 211-220.

Power, M. T. (2008). The emergence of a blended online learning environment, MERLOT Journal of Online Learning and Teaching, 4(4). pp 503-514.

Radiotjänst (1933) Konferensen för ledare av radiocirklar. Röster i Radio, No 8, 1933. Retrieved 2015-05-30 from http://runeberg.org/rostrad/1933/0362.html

Roos, G., Grepperud, G. \& Danielsen, Å. (2015). Levende studie- og læringssentra? Kompetensutmaningar i tre rurala regioner. Septentrio Reports no 3, University of Tromsø. Retrieved from http://dx.doi.org/10.7557/7.3408

Sandeen, C. (2013) Integrating MOOCS into Traditional Higher Education: The Emerging "MOOC 3.0" Era, Change: The Magazine of Higher Learning, 45:6, p. 34-39.

SCB. (2013). Population Statistics from Statistics Sweden. Retrieved from http://www.scb.se

Siemens, G. (2013). Massive open online courses: Innovation in education? In McGreal, R., Kinuthia, W. \& Marshall, S. Open Educational Resources: Innovation, Research and Practice. Vancouver: Commonwealth of Learning, Athabasca University.

UKÄ, Universitetskanslersämbetet. (2014). Universitet och Högskolor - Årsrapport 2014. Universitetskanslersämbetet.

Ödling, P. (2013). Överlever högskolan globala nätkurser? Conference talk at KTH. Retrieved 2014-04-26 fromhttps://www.youtube.com/watch?v=5g2zn8m hOo

Ödling, P., Källström, E. \& Lagergren, F. (2013). Starta University of Sweden - ett svenskt nätuniversitet. DN Debatt Dagens Nyheter. Retrieved 2015-04-26 from http://www.dn.se/debatt/starta-university-of-sweden-ett-svenskt-natuniversitet/ 
Using MOOCs at Learning Centers in Northern Sweden

Norberg, Händel and Ödling

Athabasca

University

(c) ()

This work is licensed under a Creative Commons Attribution 4.0 International License. 